\title{
Whole genome sequencing of Asia II 1 species of whitefly reveals that genes involved in virus transmission and insecticide resistance have genetic variances between Asia II 1 and MEAM1 species
}

Sonia Hussain ${ }^{1,2 \dagger}$, Muhammad Farooq ${ }^{1 \dagger}$, Hassan Jamil Malik², Imran Amin, Brian E. Scheffler ${ }^{3}$, Jodi A. Scheffler ${ }^{4}$, Shu-Sheng Liu ${ }^{5}$ and Shahid Mansoor ${ }^{1 *}$ (i)

\begin{abstract}
Background: Whiteflies (Bemisia tabaci) are phloem sap-sucking pests that because of their broad host range and ability to transmit viruses damage crop plants worldwide. B. tabaci are now known to be a complex of cryptic species that differ from each other in many characteristics such as mode of interaction with viruses, invasiveness, and resistance to insecticides. Asia $\| 1$ is an indigenous species found on the Indian sub-continent and south-east Asia while the species named as Middle East Asia Minor 1 (MEAM1), likely originated from the Middle-East and has spread worldwide in recent decades. The purpose of this study is to find genomic differences between these two species.

Results: Sequencing of the nuclear genome of Asia II 1 with Illumina HiSeq and MiSeq generated 198.90 million reads that covers $88 \%$ of the reference genome. The sequence comparison with MEAM1 identified 2,327,972 SNPs and 202, 479 INDELs. In Total, 1294 genes were detected with high impact variants. The functional analysis revealed that some of the genes are involved in virus transmission including 4 genes in Tomato yellow leaf curl virus (TYLCV) transmission, 96 in Tomato crinivirus (ToCV) transmission, and 14 genes in insecticide resistance.

Conclusions: These genetic differences between Asia II 1 and MEAM1 may underlie the major biological differences between the two species such as virus transmission, insecticide resistance, and range of host plants. The present study provides new genomic data and information resources for Asia II 1 that will not only contribute to the species delimitation of whitefly, but also help in conceiving future research studies to develop more targeted management strategies against whitefly.
\end{abstract}

Keywords: Whitefly, Asia II 1, MEAM1, Sequencing, Virus, Insecticide

\footnotetext{
* Correspondence: shahidmansoor7@gmail.com

†Sonia Hussain and Muhammad Farooq contributed equally to this work.

${ }^{1}$ National Institute for Biotechnology and Genetic Engineering, Faisalabad,

Pakistan

Full list of author information is available at the end of the article
}

(c) The Author(s). 2019 Open Access This article is distributed under the terms of the Creative Commons Attribution 4.0 International License (http://creativecommons.org/licenses/by/4.0/), which permits unrestricted use, distribution, and reproduction in any medium, provided you give appropriate credit to the original author(s) and the source, provide a link to the Creative Commons license, and indicate if changes were made. The Creative Commons Public Domain Dedication waiver (http://creativecommons.org/publicdomain/zero/1.0/) applies to the data made available in this article, unless otherwise stated. 


\section{Introduction}

Bemisia tabaci (Hemiptera: Aleyrodidae), commonly known as 'whiteflies' are phloem sap sucking pests some of which have become a major constraint to important food, fiber and ornamental crops worldwide. The whiteflies can infest as many as 1000 plant species [1] and they damage host plants by infestation, but more importantly by transmitting plant viruses. These whiteflies can potentially vector over 300 plant viruses, mostly viruses in the genus Begomovirus [2]. Major crops affected by B. tabaci-transmitted viruses on a global scale include cotton, cassava, tomato, sweet potato, cucurbits and other crop plant species.

Whiteflies (B. tabaci) are now known to be as a cryptic species complex, based on recent molecular phylogenetic analyses and evidence of reproductive incompatibility [3, 4]. These putative whitefly species differ in many biological aspects such as host range [1], resistance to insecticides [5, 6], specificity and capacity of virus transmission [7, 8] and composition of harbored symbionts [9]. Although the use of $\geq 3.5 \% \mathrm{mtCO}$ divergence as the criterion for species delimitation has been occasionally shown to be inadequate [10], it has been widely used to differentiate species. Based on sequence divergence of mtCOI $(\geq$ $3.5 \%$ divergence), B. tabaci has been deduced to include more than 39 cryptic species that are morphologically indistinguishable but genetically distinct [11-13].

The long-term association between begomoviruses and whitefly has brought some co-evolved adaptations [14] that allow them to live in equilibrium. Begomoviruses are single-stranded (ss) DNA viruses that are transmitted mostly in a persistent circulative manner. Once ingested through the stylet, these plant viruses move across the mid gut membrane and then via hemolymph translocate to salivary glands and from there these are egested while feeding [15]. In circulation of viruses, mid gut and salivary glands are the main barriers to overcome $[16,17]$. Some mid gut proteins and proteins produced by endosymbionts in hemolymph are associated with circulation of viruses in whitefly. These interacting proteins are the main points which lead to the differentiation of cryptic species on the basis of specificity and capacity of virus transmission. The heat shock protein HSP70 is co-localized with Tomato yellow leaf curl virus (TYLCV) coat protein within midgut epithelial cells and inhibits virus transmission [18]. Knottin1 restricts the virus (TYLCV) amount in whitefly and thus shields the whitefly against its deleterious effects [19]. While cyclophilin B enhances the translocation of virus from mid gut to hemolymph [20]. Another protein peptidoglycan recognition protein (BtPRPG) is involved in whitefly immunity and has a potential binding site for TYLCV. Its co-localization with TYLCV is also reported within the midgut [21]. Endosymbionts which have been living in whitefly for millions of years [22] are also involved in virus transmission. Different cryptic species harbor different endosymbionts. Endosymbionts reside in bacteriocytes and some of them (e.g. Hamiltonella) produce GroEL homologue in the hemolymph which helps in virus circulation in whitefly.

Middle East-Asia Minor 1 (MEAM1, formerly known as "biotype B") and Mediterranean (MED, formerly "Q biotype") are globally important cryptic species of whitefly $[23,24]$ because of their invasiveness and broad host range. The two species originated in the Middle East regions, but are now reported from many regions of the world, and its presence has also been well reported in the southern Sindh region of Pakistan [25, 26]. Asia 1 and Asia II 1 are two species of whitefly indigenous to Pakistan, with Asia II 1 being the most prevalent whitefly in the central region of the country [26]. The different species of whitefly recorded from Pakistan have been shown to differ in many aspects including virus transmission, insecticide resistance, and host range. For example, MEAM1 is more efficient than Asia II 1 in transmitting Tomato yellow leaf curl virus (TYLCV) [27]. In a study in Vietnam where Asia II 1 is indigenous, Asia II 1 is reported to be more efficient in transmitting Tomato leaf curl Hainan virus (ToLCHnV) than that of TYLCV, while MEAM1 is more efficient in transmitting TYLCV than ToLCHnV [28]. Asia II 1 has been reported to be the most abundant species of whitefly in areas of high incidence of cotton leaf curl disease (CLCuD) in Pakistan and the western region of India. Two recent studies in China [17, 29] directly compared the transmission efficiency of begomoviruses by MEAM1, Asia II 1 and two more species, and showed that among these species Asia II 1 is the most efficient in transmitting both Cotton leaf curl Multan virus (CLCu$\mathrm{MuV}$ ) and Tobacco curly shoot virus (TbCSV). Apart from differences in transmission efficiency of viruses, these species of whiteflies also differ in insecticide resistance [30] and host plant preference [31]. However, the physiological and molecular mechanisms underlying the differences between species of whitefly are yet poorly known.

Over the past several years, next generation sequencing (NGS) technology has emerged as an innovative approach to high-throughput sequencing [32], and the rapid development of this modern technology provides us an unprecedented opportunity to understand and explore numerous genetic findings, which can help to improve our research on the physiology and molecular biology of the whiteflies. These results can also provide new knowledge and concepts for the development of novel strategies and technology to manage whitefly pests and the viral disease agents they vector. In this study, our aim is to unravel some genetic information from Asia II 1 and MEAM1, the two major whitefly pests in Pakistan. First, with access to the data of MEAM1 [4], we performed high throughput sequencing of Asia II 1 
and aligned with that of MEAM1, to identify major genomic differences between the two species. We detected some high impact variants in genes (which were previously reported as differentially expressed genes) that have been predicted to be associated with virus transmission and insecticide resistance.

\section{Results}

\section{Mapping summary of nuclear genome}

Genome sequencing of Asia II 1 with Illumina HiSeq and MiSeq generated a total of $31.15 \mathrm{~Gb}$ of data comprising 198.90 million reads with read size 100 and 300 bp (the summary of raw data generated from each of seven libraries is given in Additional file 1). Approximately $91 \%$ of the reads passed the quality control criteria and 82 to $86 \%$ of these reads were mapped correctly to the reference genome. The available sequence from the reference genome is $615 \mathrm{Mb}$ [4] of the assessed total genome size of $\sim 680-690 \mathrm{Mb}$ as estimated in a previous study [33] using both flow cytometry and Kmer analysis. These reads covered $88 \%$ of the reference genome. The mean read length was $159 \mathrm{bp}$. The summary of the sequencing and mapping is shown in Table 1. The average depth of coverage of genome after filtration was $34 \mathrm{X}$. Total length of the coding region of the reference genome is $44.43 \mathrm{Mb}, 51 \%$ of which was covered with more than $5 \mathrm{X}$ depth of coverage, and $53 \%$ of the number of coding regions with $100 \%$ of length have at least $5 \mathrm{X}$ depth of coverage. The mean coverage of the coding region is $32 \mathrm{X}$. Figure 1 displays

Table 1 Mapping Summary

\begin{tabular}{ll}
\hline Total NGS Library & 7 \\
Total Insert Size & 550 \\
Sequencer & IlluminaHiSeq2500 \\
\&MiSeq & (HiSeq: 14GB) \\
Total Raw Data Generate & (MiSeq: $16 \mathrm{~Gb})$ \\
& Total: $31.15 \mathrm{~Gb}$ \\
& 47.34 X \\
Average Coverage & $34.52 \times$ \\
Average Coverage After & \\
Filtration & HiSeq: 142605246 \\
Total No of Reads & MiSeq: 56300942 \\
Generate & Total: 198906188 \\
& $181,434,767$ \\
Total No of Reads Quality & $156,293,812$ (86\%) \\
Passed & $149,439,368$ (82\%) \\
Total No of Reads Mapped & \\
Total No of Reads Mapped & $88 \%$ \\
Properly & 159 bp \\
Reference Genome Covered & \\
Mean Read Length & \\
\hline
\end{tabular}

the different number of coding regions with different lengths having at least $5 \mathrm{X}$ depth of coverage. Approximately 8366 coding regions have at least $5 \mathrm{X}$ coverage with full length genes.

\section{Variant statistics}

After variant calling and two times filtration with Genome Analysis Tool Kit (GATK), total number of 2,530, 451 high quality variants were discovered. Variant annotations and effect prediction through SnpEff resulted in 3,504,011 effects. Effects are greater in number than number of variants as one variant could have more than one effect. For example, one variant could be nonsynonymous for one gene while being downstream to another. A variant statistics summary is given in Table 2 (raw variant calling data and the data after each filtration is provided in Additional file 2). Approximately 2,327, 972 SNPs and 202,479 INDELs were detected. In eight amplified regions ranging in size from 500 to $600 \mathrm{bp}$, there are 96 SNPs which were all validated through Sanger sequencing. The primers pairs list and validated SNPs positions are given in Additional file 4. The initial average variant rate was $1 / 20 \mathrm{bp}$, but that was decreased to $1 / 235 \mathrm{bp}$ after filtration (when depth of read coverage at a variant point was increased to $30 \mathrm{X}$ in variant calling criterion). Variant rate also varied in different regions, the maximum variant rate recorded was $1 / 27 \mathrm{bp}$ and minimum variant rate was $1 / 32,808 \mathrm{bp}$. Transition to transversion ratio is 1.71 and heterozygous to homozygous variant ratio is 0.05 . In this study, insertions and deletions ranging from 1 to $100 \mathrm{bp}$ were considered as INDELs. The maximum number of INDELs were $1 \mathrm{bp}$ in length while lowest number of INDELs were of 14, 15, $20,21,23,28,33,69,89$ or $100 \mathrm{bp}$ in length. The distribution and types of variant effects in the whole genome are given in Table 3. According to functional effects of variants, these were distributed into three classes; silent (69.94\%), missense (29.77\%) and nonsense (0.29\%).

Among the total estimated genes in whitefly MEAM1 $(15,664), 1294$ genes were found to have high impact variants in this data. These genes were selected for further analysis of ontology. The distribution and number of variants and their effects in different genic regions are given in Fig. 2. The number of genes in each class of high impact variants are also provided in Table 4.

\section{Gene ontology}

Coding regions that have high impact variants (1294 genes) were selected for gene ontology analysis. The Blast2GO results are shown in Fig. 3. The functions of these were classified into three groups: biological process (BP), molecular function (MF), and cellular components (CC). The greatest number of genes were associated with the BP category. IDs of genes associated with each sub 


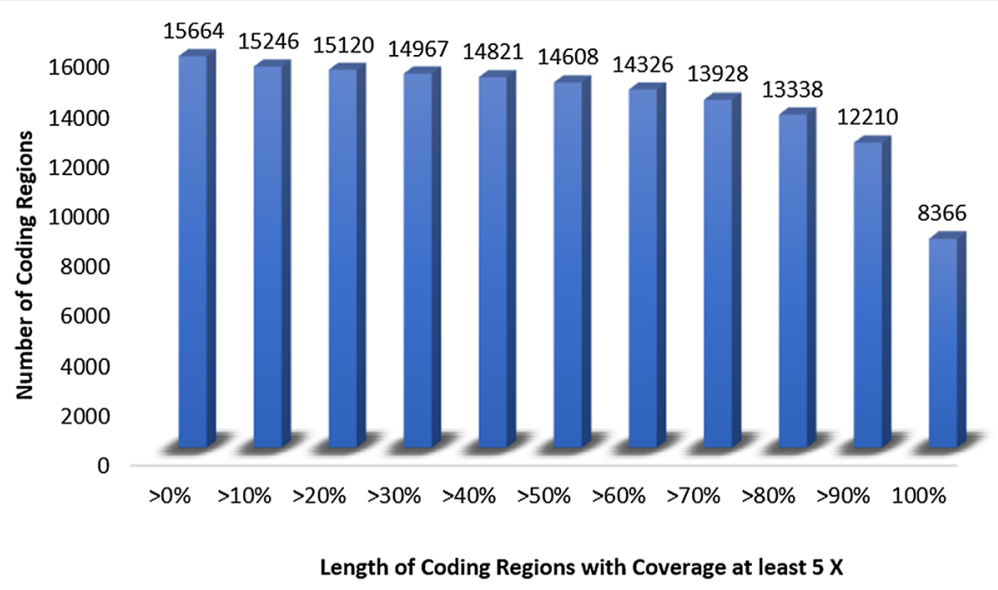

Fig. 1 Total coding regions are 15,664. All the coding regions with less than 10\% each of their length are covered with at least $5 X$ coverage, 53\% of coding regions (8366) with full length are covered with at least 5X coverage

category of these three functional classes are given in Additional file 3. Additional file 7 shows the associated pathways for the genes (with high impact variants), which were predicted by Blast2GO.

\section{Genes involved in virus transmission and insecticide resistance}

Fourteen genes of MEAM1 that were reported for potential involvement in insecticide resistance [4] and 96 genes which were reported to be associated with virus transmission [6] were expected to be high impact variants between Asia II 1 and MEAM1. In the present study, there were 15 high impact variants found in 14 genes which could potentially be involved in insecticide resistance. High impact variants include frame shift, start loss, stop gain, splice acceptor and splice donor. These lead to truncated or modified proteins with partial or complete loss of function. There is also a chance that because of these mutations some of the proteins may gain more efficiency rather than to be dis-functional. These 14 genes belong to 4 gene families: acetylcholinesterase

Table 2 Variant Statistics

\begin{tabular}{ll}
\hline Number of variants & $2,530,451$ \\
Number of effects & $3,504,011$ \\
Variant rate & $1 / 235$ bases \\
SNP & $2,327,972$ \\
INS & 103,960 \\
DEL & 98,519 \\
Missense / Silent & 0.4257 \\
Ts/Tv ratio & 1.7147 \\
Heterozygous & 122,045 \\
Homozygous & $2,349,906$ \\
Heterozygous/Homozygous & 0.05193612 \\
\hline
\end{tabular}

Table 3 Classification of effects and their number in the whole genome

\begin{tabular}{|c|c|c|c|}
\hline \multicolumn{2}{|l|}{ Type of Effects } & \multicolumn{2}{|c|}{ No of Effects } \\
\hline & & Count & Percent \\
\hline High Effect & Total & 1821 & 0.052 \\
\hline \multicolumn{2}{|c|}{ Splice acceptor variant } & 96 & 0.003 \\
\hline \multicolumn{2}{|c|}{ Splice donor variant } & 135 & 0.004 \\
\hline \multicolumn{2}{|l|}{ Start loss } & 56 & 0.002 \\
\hline \multicolumn{2}{|l|}{ Stop gain } & 371 & 0.003 \\
\hline \multicolumn{2}{|l|}{ Stop lost } & 96 & 0.003 \\
\hline \multicolumn{2}{|l|}{ Frame shift } & 1102 & 0.031 \\
\hline Moderate Effect & Total & 35,583 & 2.724 \\
\hline \multicolumn{2}{|c|}{ Conservative inframe deletion } & 49 & 0.001 \\
\hline \multicolumn{2}{|c|}{ Conservative inframe insertion } & 83 & 0.002 \\
\hline \multicolumn{2}{|c|}{ Disruptive inframe deletion } & 98 & 0.003 \\
\hline \multicolumn{2}{|c|}{ Disruptive inframe insertion } & 74 & 0.002 \\
\hline \multicolumn{2}{|c|}{ Missense variant } & 35,285 & 1.004 \\
\hline Low Effect & Total & 95,439 & 1.015 \\
\hline \multicolumn{2}{|c|}{ 5' UTR premature start gain } & 3020 & 0.086 \\
\hline \multicolumn{2}{|c|}{ Splice region variant } & 10,980 & 0.312 \\
\hline \multicolumn{2}{|l|}{ Stop retained } & 106 & 0.003 \\
\hline \multicolumn{2}{|c|}{ Synonymous variant } & 83,150 & 2.366 \\
\hline \multicolumn{2}{|c|}{ Initiator codon/ non syn start } & 15 & 0 \\
\hline Modifier Effects & Total & $3,371,168$ & 96.209 \\
\hline \multicolumn{2}{|l|}{ 3' UTR } & 174,811 & 4.974 \\
\hline \multicolumn{2}{|l|}{ 5' UTR } & 23,577 & 0.671 \\
\hline \multicolumn{2}{|l|}{ Downstream } & 485,837 & 13.823 \\
\hline \multicolumn{2}{|l|}{ Upstream } & 421,908 & 12.041 \\
\hline \multicolumn{2}{|c|}{ Non-coding transcript } & 470 & 0.013 \\
\hline \multicolumn{2}{|l|}{ Intron variant } & $1,479,087$ & 42.082 \\
\hline \multicolumn{2}{|c|}{ Intergenic regions } & 794,375 & 22.67 \\
\hline
\end{tabular}




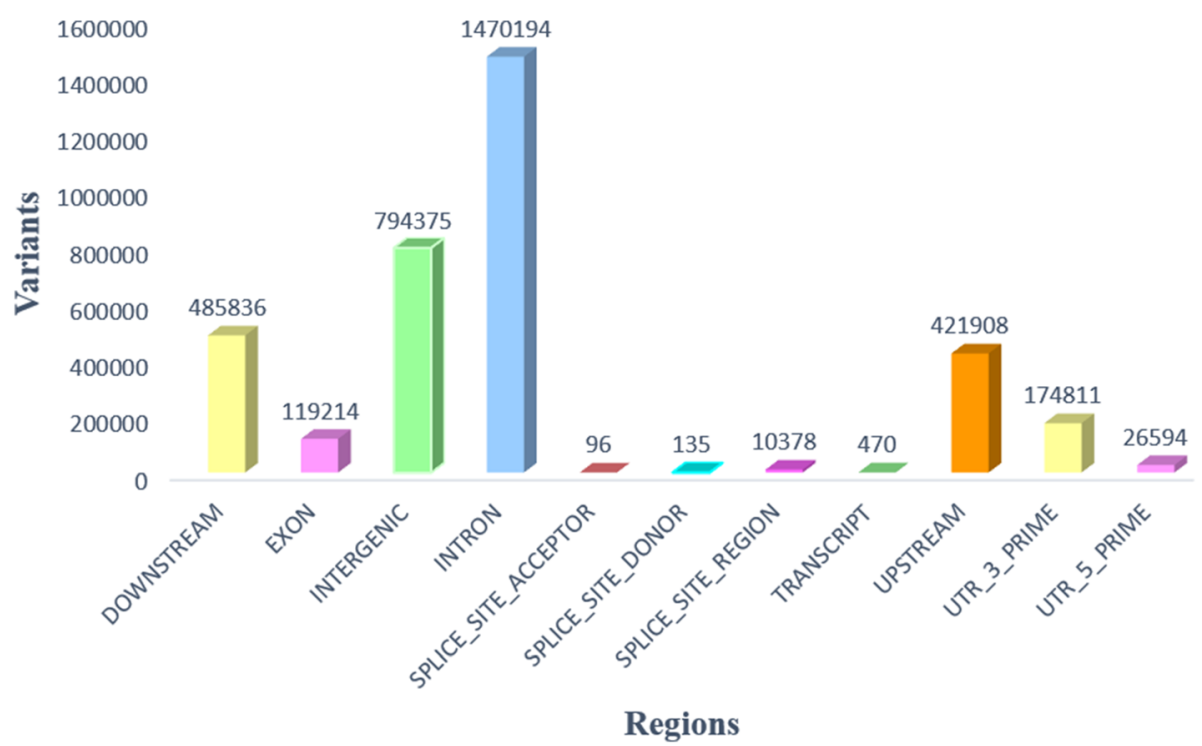

Fig. 2 Distribution of variants in different genic regions

like protein, cathepsin (B, F, cathepsin L like), Cytochrome $\mathrm{P} 450$, and phosphatidylethanolamine-binding protein 1. A list of these insecticide resistance gene IDs is shown in Table 5 and those for virus transmission in Table 6 (TYLCV) and 7 (ToCV). All the genes described in Table 5 are reported for the potential involvement in insecticide resistance by Chen et al., [4], and those for virus transmission in Table 6 and Table 7 are reported by Hasegawa et al., [34] and Kaur et al., [6] respectively.

\section{Structural variants}

Structural variants were predicted through CNVnator in which the method of detection of structural variants is based on assessing the read of depth of the mapping genome. With CNVnator, among all the structural variants (duplications, deletions, insertions, inversions and translocations), some duplications were detected in the present study. Duplications with more than $1.5 \mathrm{cnv}$ value are enlisted in Table 8 with their positions on the scaffolds and included genes in them. Functional annotations of these

Table 4 Number of variant genes in each sub-class of high effects. One gene may have more than one effect and same gene may count in more than one category of high effects

\begin{tabular}{ll}
\hline Type of High Effects & No of Genes \\
\hline Splice acceptor variant & 92 \\
Splice donor variant & 129 \\
Start Loss & 55 \\
Stop gain & 346 \\
Stop lost & 91 \\
Frame shift & 765 \\
Total & 1294 \\
\hline
\end{tabular}

genes are presented in Additional file 6. Copy number variations were detected by CNVkit, which are described in Additional file 5. The structural variants in this study is not a comprehensive data and it is necessary to mention that reference genome is a draft genome that is about $90 \%$ of total estimated genome $(\sim 680-690 \mathrm{Mb})$ and in present study, $88 \%$ of this draft genome was covered with mapping reads. When the complete reference genome would be used to detect the structural variants, the results may include some more structural variants.

\section{Discussion}

Whitefly divergence into different distinct genotypes initiates the question whether the divergence results in a complex of different biotypes or it is a complex of different species! In order to resolve the divergence of whitefly question, it would be helpful to set criterion for sorting the different biotypes of whitefly and set a limit above which the difference is sufficient to declare new species status. Biological features e.g. virus transmission capacity, gut microbe diversity, host range, capacity to induce physiological changes in host plants, intermating capabilities, and capacity to spread widely have been used to differentiate cryptic species. Some of the genetic groups share common biological characters and some of the characters also show within group variability. Thus, most of the differences are uninformative or unable to resolve the cryptic species of whitefly. Molecular markers (such as AFLP, RAPD, 16S, CAPS, SCAR and $\mathrm{mtCOI}$ ) have been used to show genetic differences between genotypes. The $3.5 \%$ genetic difference in terms of mtCOI sequences, differentiates almost all reproductively isolated groups according to available biological 


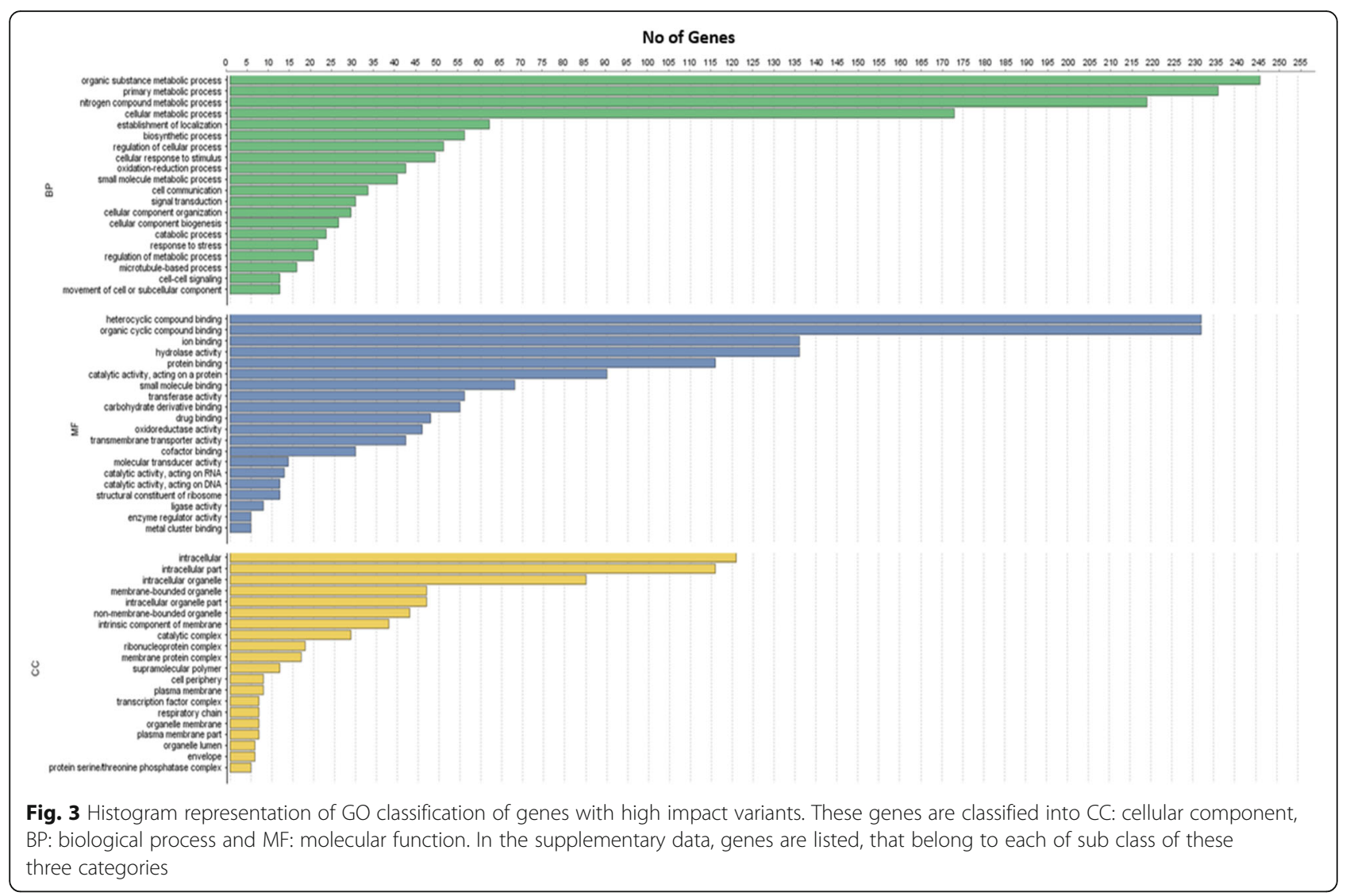

data. But some reports show disagreements with the outcomes using partial sequences of mitogenome. For example, a recent study [35], using genome wide analysis, suggested that MEAM2 might not be a separate genetic group but fall entirely into the MEAM1 group, whereas previously it was considered as a separate genetic group using mitochondrial genes. A similar phenomenon was observed in a recent study [36], where a combined analysis of experimental biological data with mitogenome sequences proposed that the African silverleafing (ASL)

Table 5 Genes potentially involved in insecticide resistance with variants between Asia II 1 and MEAM1

\begin{tabular}{llll}
\hline Gene ID & Annotation & Type of Variant & Variant Position \\
\hline Bta08717 & Acetylcholinesterase-like protein & Srame Shift & Scaffold325:2419087 \\
Bta12286 & Cathepsin B & Start lost & Scaffold562:2252138 \\
Bta06690 & Cathepsin F & Scaffold2605:1316025 \\
Bta07152 & Cathepsin L-like protease & Frame Shift & Scaffold2737:56518 \\
Bta02560 & Cathepsin L-like protease & Frame Shift & Scaffold132:3684567 \\
Bta04696 & Cytochrome P450 & Splice acceptor & Scaffold1685:811440 \\
Bta06044 & Cytochrome P450 & Scaffold231:1494714 \\
Bta01556 & Phosphatidylethanolamine-binding protein & Stop lost & Scaffold1224:613594 \\
Bta01355 & Phosphatidylethanolamine-binding protein 1 & Scaffold1195:116803, \\
& & Frame Shift & Scaffold1195:118926 \\
Bta15207 & Phosphatidylethanolamine-binding protein 1 & Start lost, splice & Scaffold923:587527 \\
Bta07891 & Phosphatidylethanolamine-binding protein 1 & Start lost & Scaffold300:6735496 \\
Bta12136 & Phosphatidylethanolamine-binding protein 1 & splice donor & Scaffold545:18333 \\
Bta13188 & Phosphatidylethanolamine-binding protein 1 & Frame Shift & Scaffold637:1563358 \\
Bta02907 & Phosphatidylethanolamine-binding protein, putative & Splice acceptor & Scaffold14:2449776 \\
\hline
\end{tabular}


Table 6 List of gene IDs which are potentially involved in TYLCV virus transmission and have genetic variants between Asia II 1 and MEAM1

\begin{tabular}{llll}
\hline Gene ID & Annotation & Type of Variant & Variant Position \\
\hline Bta10341 & Aldo-keto reductase & Frame Shift & Scaffold 403:3624744 \\
Bta04072 & Elicitin-like protein 6 & Frame Shift & Scaffold161:5952976 \\
Bta02276 & $\begin{array}{l}\text { Ubiquitin carboxyl- } \\
\text { terminal hydrolase }\end{array}$ & Frame Shift & Scaffold130:858376 \\
Bta14634 & Unknown protein & $\begin{array}{l}\text { Frame Shift, } \\
\text { Splice Donor }\end{array}$ & $\begin{array}{l}\text { Scaffold811: 176696, } \\
\text { Variant }\end{array}$ \\
& & & \\
\hline
\end{tabular}

genotype, formerly treated as MED, may form a separate cryptic species. Thus, in view of these reports, species delimitation across the $B$. tabaci species complex requires data in addition to sequence divergence of mtCOI. Many recent reports show that species delimitation of a cryptic species complex requires a multi-method approach that integrates genetic differentiation, biological character, DNA barcoding, molecular phylogenetic analysis and possibly other biological features. In this regard, our study provides whole genome nuclear variants data, which will be useful to improve species delimitation of the B. tabaci species complex. It is also necessary to mention that although we detected all these variants between the two species Asia II 1 and MEAM1, but it may also possible that some of the variants may segregate within the same species.

In this study, we have sequenced the genome of the Asia II 1 species of whitefly and have used published transcriptomic data to infer biological differences between Asia II 1 and MEAM1. The sequencing of Asia II 1 not only provided new genomic resources for Asia II 1, but its comparative study with MEAM1 also provided insight into the comprehensive genetic differences between them.

With Blast2GO analysis, high impact variant genes were analyzed to identify the involvement of these genes in molecular pathways. The goal was to find out how genetic variances may alter or affect pathways which may then help in understanding the biological differences between the two species. Signal transduction pathways were considered as one of main points where gene alterations might help the whitefly to deal with any changes in the environment or inside the whitefly cells. Phosphatase and kinases are well-known enzymes in signal transduction pathways [37] as they activate or deactivate the functional proteins by either phosphorylation or dephosphorylation. Kinase and phosphatase functions in antagonistic ways as kinase initiates the phosphorylation and phosphatase removes the phosphate group from its substrate protein. In Additional file 7 , it is noticeable that most of the genes are encoding phosphatase and kinase in different pathways e.g. phosphatase in $\mathrm{T}$ cell receptor signaling pathways, purine and thymine metabolism, and kinase in drug metabolism (important for pesticide resistance) and phosphatidylinositol signaling pathways. Genetic variants of these genes may alter their systematic regulatory role in biological functions.

Another prominent group of genes comprised "oxidase, dehydrogenase and reductase" enzymes performing functions in oxidative phosphorylation, amino acid (glycine, serine, threonine, valine, isoleucine, arginine and proline) metabolism, steroid degradation and biosynthesis, and biosynthesis of antibiotics. The robustness of a phloem sap sucking pest depends on the amino acid and carbohydrate contents of phloem sap of their host [38] as well as on their processing power of amino acids. For example, a Florida strain of whitefly processes more phloem sap that allows it to have more expanded host range [39]. Phloem sap lacks some essential amino acids and vitamins, so phloem sap sucking pests rely heavily on endosymbionts for some essential amino acids. There are number of genes which are present in more than one pathway for example Bta13274 encodes an oxidase involved in biosynthesis of antibiotics as well as arginine and proline metabolism, indirectly contributes to environmental fitness. A previous study reported that MEAM1 performed better than Asia II 1 on many commonly cultivated crops in China [40], and in another study MEAM1 showed the ability to adapt to unsuitable hosts [41]. Genetic variants in these genes may provide clues to the differential capacity of Asia II 1 and MEAM1 to adapt to changing environments.

Some recent studies report genes showing differential expression upon treatment of insecticide or virus infection. In our data, we identified high impact variants in 14 genes associated with insecticide resistance, 4 genes involved in TYLCV transmission, and 96 genes involved in ToCV transmission. The cathepsin gene family is involved in both insecticide resistance and ToCV transmission. Our results identified high impact variants in cathepsin B (3 genes), cathepsin F (1 gene) and cathepsin L-like genes (3 genes) that are involved in insecticide resistance and $\mathrm{ToCV}$ transmission. Cathepsins are proteases involved in many biological functions such as protein degradation, apoptosis, and signaling, and their activity in lysosomes has been broadly connected to virus transmission. The cathepsin B family is expanded in B. tabaci and also a novel clade of cathepsin L-like genes is identified in comparison to 15 other arthropods [4] which lead to the prediction of a possible contribution of cathepsin in virus acquisition or other responses that are involved in whitefly-virus interactions. Another important family in which genetic variants were found, associated with insecticide resistance is cytochrome P450 [42]. Two high impact variants were identified in two CYP 450 genes (Bta04696 and Bta06044). Chen et al., [4] inferred the involvement of these genes in insecticide resistance in MEAM1 on the basis of their 
Table 7 List of gene IDs which are potentially involved in ToCV virus transmission and have genetic variants between Asia II 1 and MEAM 1

\begin{tabular}{|c|c|c|c|}
\hline Gene ID & Gene Name & Type of Variants & Scaffold:Snp Position \\
\hline Bta08892 & $70 \mathrm{kDa}$ heat shock protein & Frame shift & Scaffold3328:264318 \\
\hline Bta01665 & AAA-ATPase-like domain-containing protein & frame shift & Scaffold1224:5022892 \\
\hline Bta12603 & AAA-ATPase-like domain-containing protein & stop gain & Scaffold597:2078628 \\
\hline Bta05346 & Afadin, putative & stop lost & Scaffold199:1272506 \\
\hline Bta11978 & Alpha-glucosidase & Frame shift & Scaffold521:859550 \\
\hline Bta01804 & $\begin{array}{l}\text { Ankyrin repeat and LEM domain-containing } \\
\text { protein }\end{array}$ & Frame shift & Scaffold123:4405622 \\
\hline Bta01772 & Cathepsin B & Frame shift & Scaffold123:2832350 \\
\hline Bta07402 & Cathepsin B & Frame shift & Scaffold2816:1342943 \\
\hline Bta02120 & Cathepsin L-like protease & Frame shift & Scaffold1261:554552 \\
\hline Bta02560 & Cathepsin L-like protease & Frame shift & Scaffold132:3684567 \\
\hline Bta07152 & Cathepsin L-like protease & Frame shift & Scaffold2737:56518 \\
\hline Bta06739 & Cation transport regulator-like protein 1 & Frame shift & Scaffold2605:2569958 \\
\hline Bta08022 & CG13675, isoform D & Frame shift & Scaffold3040:3058531 \\
\hline Bta04412 & CG14375 & Frame shift & Scaffold165:195426 \\
\hline Bta03710 & CG17612, isoform A & splice acceptor variant & Scaffold155:194033 \\
\hline Bta11746 & CG7120, isoform F & splice donor, frame shift & Scaffold52:4009995 \\
\hline Bta10928 & Chromodomain Y-like protein 2 & Frame shift & Scaffold477:1214758 \\
\hline Bta12891 & Citron Rho-interacting kinase & Frame shift & Scaffold613:2332964 \\
\hline Bta02184 & Cystatin & frame shift & Scaffold128:1309680 \\
\hline Bta07162 & DDB1-and CUL4-associated factor & start loss,stop gain, & $\begin{array}{l}\text { Scaffold2737:410077, } \\
\text { Scaffold2737:419749 }\end{array}$ \\
\hline Bta07434 & $\begin{array}{l}\text { DNA-directed RNA polymerase, omega } \\
\text { subunit family protein }\end{array}$ & stop gain, frame shift & Scaffold2890:209245 \\
\hline Bta14689 & $\begin{array}{l}\text { Dolichyl-diphosphooligosaccharide--protein } \\
\text { glycosyltransferase subunit STT3B }\end{array}$ & splice acceptor variant & Scaffold811:2521172 \\
\hline Bta15680 & E3 ubiquitin-protein ligase TTC3 & Frame shift & Scaffold988:3252798 \\
\hline Bta03681 & $\begin{array}{l}\text { Eukaryotic translation initiation factor } 3 \\
\text { subunit A }\end{array}$ & Frame shift & Scaffold1512:1481746 \\
\hline Bta14560 & Galectin & Frame shift & Scaffold809:3964391 \\
\hline Bta10009 & General transcription factor $3 C$ polypeptide 2 & Frame shift & Scaffold382:2610001 \\
\hline Bta04387 & GH16255p & splice acceptor variant & Scaffold1647:2597569 \\
\hline Bta00770 & GK11989 & stop lost, frame shift & Scaffold1 103:753116 \\
\hline Bta01833 & Klarsicht, isoform $\mathrm{E}$ & stop gain, frame shift & Scaffold123:5600056 \\
\hline Bta09051 & Laminin subunit beta-1 & stop gain & Scaffold338:1218247 \\
\hline Bta01704 & Loquacious & Frame shift & Scaffold123:255863 \\
\hline Bta03800 & Lysosomal-trafficking regulator & Frame shift & Scaffold155:4253425 \\
\hline Bta05467 & Major royal jelly-related protein & stop lost & Scaffold199:6871677 \\
\hline Bta05773 & $\begin{array}{l}\text { NADH dehydrogenase [ubiquinone] } 1 \\
\text { alpha subcomplex subunit } 12\end{array}$ & stop gain & Scaffold2229:151223 \\
\hline Bta15454 & Neuroendocrine convertase 1 & Frame shift & Scaffold959:3096344 \\
\hline Bta10191 & Nidogen-2 & stop gain & Scaffold3978:2723 \\
\hline Bta13257 & Protein patched & Frame shift & Scaffold641:259689 \\
\hline Bta15368 & Protein phosphatase $1 \mathrm{~L}$ & Frame shift & Scaffold959:15812 \\
\hline Bta13589 & Protein unc-45-like protein A & Frame shift & Scaffold651:2187902 \\
\hline
\end{tabular}


Table 7 List of gene IDs which are potentially involved in ToCV virus transmission and have genetic variants between Asia II 1 and MEAM 1 (Continued)

\begin{tabular}{|c|c|c|c|}
\hline Gene ID & Gene Name & Type of Variants & Scaffold:Snp Position \\
\hline Bta02051 & Regucalcin & start loss & Scaffold1240:111531 \\
\hline Bta10926 & Replication factor-a protein 1 & Frame shift & Scaffold477:1149858 \\
\hline Bta12190 & Sortilin-related receptor & Frame shift & Scaffold545:2426274 \\
\hline Bta02847 & Sulfotransferase & stop gain & Scaffold14:67127 \\
\hline Bta08229 & Symplekin & splice acceptor variant & Scaffold317:609334 \\
\hline Bta07946 & $\begin{array}{l}\text { Terribly reduced optic lobes, } \\
\text { isoform AN }\end{array}$ & splice acceptor & Scaffold3040:556936 \\
\hline Bta05242 & Transcriptional protein SWT1 & Frame shift & Scaffold1898:321532 \\
\hline Bta09856 & Trehalase & stop gain & Scaffold374:3016858 \\
\hline Bta03298 & Trypsin-like serine protease & stop lost & Scaffold147:7182519 \\
\hline Bta09090 & Tudor domain protein & stop lost & Scaffold338:1990664 \\
\hline Bta08596 & $\begin{array}{l}\text { Tudor domain-containing } \\
\text { protein } 1\end{array}$ & Frame shift & Scaffold322:4722919 \\
\hline Bta03892 & $\begin{array}{l}\text { Ubiquitin carboxyl-terminal } \\
\text { hydrolase }\end{array}$ & start lost & Scaffold1580:568946 \\
\hline Bta01518 & Unknown protein & stop gain & Scaffold1214:734963 \\
\hline Bta01571 & Unknown protein & Frame shift & Scaffold1224:1139169 \\
\hline Bta01615 & Unknown protein & Frame shift & Scaffold1224:3224397 \\
\hline Bta02665 & Unknown protein & Frame shift & Scaffold1339:520464 \\
\hline Bta02767 & Unknown protein & Frame shift & Scaffold137:1379435 \\
\hline Bta02836 & Unknown protein & Frame shift & Scaffold139:1098948 \\
\hline Bta02920 & Unknown protein & Frame shift & Scaffold14:3202002 \\
\hline Bta03301 & Unknown protein & stop gain, frame shift & Scaffold147:7328434 \\
\hline Bta03426 & Unknown protein & stop gain & Scaffold1496:690294 \\
\hline Bta03435 & Unknown protein & Frame shift & Scaffold1496:1047497 \\
\hline Bta04551 & Unknown protein & Frame shift & Scaffold165:5163918 \\
\hline Bta04829 & Unknown protein & Frame shift & Scaffold17:652047 \\
\hline Bta04921 & Unknown protein & Frame shift & Scaffold17:652047 \\
\hline Bta05143 & Unknown protein & stop gain & Scaffold18461:1072084 \\
\hline Bta05268 & Unknown protein & stop gain, frame shift & Scaffold1971:32055 \\
\hline Bta05546 & Unknown protein & Frame shift & Scaffold2013:237841 \\
\hline Bta05683 & Unknown protein & Frame shift & Scaffold2124:427571 \\
\hline Bta05758 & Unknown protein & Frame shift & Scaffold2225:1204179 \\
\hline Bta05761 & Unknown protein & stop gain & Scaffold2225:1258041 \\
\hline Bta05893 & Unknown protein & stop gain & Scaffold226:1397519 \\
\hline Bta06123 & Unknown protein & splice donor & Scaffold231:3876649 \\
\hline Bta07727 & Unknown protein & Frame shift & Scaffold300:708005 \\
\hline Bta07839 & Unknown protein & stop gain & Scaffold300:4527825 \\
\hline Bta08000 & Unknown protein & stop gain, frame shift & Scaffold3040:2567504 \\
\hline Bta08242 & Unknown protein & Frame shift & Scaffold317:1074159 \\
\hline Bta08287 & Unknown protein & stop gain & Scaffold320:265593 \\
\hline Bta08375 & Unknown protein & stop gain & Scaffold320:3813827 \\
\hline Bta08462 & Unknown protein & Frame shift & Scaffold322:385722 \\
\hline Bta08745 & Unknown protein & Frame shift & Scaffold325:3471439 \\
\hline
\end{tabular}


Table 7 List of gene IDs which are potentially involved in ToCV virus transmission and have genetic variants between Asia II 1 and MEAM 1 (Continued)

\begin{tabular}{llll}
\hline Gene ID & Gene Name & Type of Variants & Scaffold:Snp Position \\
\hline Bta10862 & Unknown protein & splice acceptor variant & Scaffold471:791307 \\
Bta11840 & Unknown protein & Frame shift & Scaffold52:7764853 \\
Bta12278 & Unknown protein & stop gain & Scaffold562:2009445 \\
Bta12668 & Unknown protein & start lost & Scaffold607:1307735 \\
Bta12727 & Unknown protein & Frame shift & Scaffold607:2833985 \\
Bta13235 & Unknown protein & Frame shift & Scaffold64:63239 \\
Bta13327 & Unknown protein & splice donor & Scaffold641:3718364 \\
Bta13745 & Unknown protein & Frame shift & Scaffold657:1097200 \\
Bta13859 & Unknown protein & stop gain & Scaffold67:1393372 \\
Bta13954 & Unknown protein & Frame shift & Scaffold699:810303 \\
Bta15302 & Unknown protein & Frame shift & Scaffold942:1732675 \\
Bta15415 & Unknown protein & Frame shift & Scaffold959:1270849 \\
Bta07758 & Zinc finger protein & Frame shift & Scaffold300:1778386 \\
Bta06175 & Zinc finger protein 227 & stop gain & Scaffold232:1822927 \\
Bta08766 & Zinc finger protein 34 & Frame shift & Scaffold325:3972542 \\
Bta11305 & Zinc finger protein 845 & Frame shift & Scaffold493:2884873 \\
\hline
\end{tabular}

differential expression upon treatment with insecticides. Another gene that encodes a heat shock protein known to be involved in virus transmission [18] has frame shift variant in Asia II 1. Three genes which have high impact variants and are linked to ToCV transmission are associated with three KEGG pathways: oxidative phosphorylation (Bta05773), T cell receptor signaling pathway (Bta15368), and sucrose and starch metabolism (Bta09856). Bta09856 encodes trehalase a glycosidase which convert trehalose (major sugar reserve in insects play a vital role as an instant source of energy and in dealing with abiotic stresses) into glucose in sucrose and starch metabolism. The inhibition of trehalase causes abnormal growth and unsuccessful stress recovery [43]. Inhibition of trehalase provides promising area towards formulating strategy for insect control. There are also some genes with unknown functions, associated with transmission of ToCV [6]. We reported the genetic variants between Asia II 1 and MEAM1 for these genes, and future annotation of these unknown genes may provide further clues about the mechanism through which whitefly interact with a virus. This comprehensive data set of variations between indigenous and invasive species provide insights into the variations in mechanisms which give different attributes to whitefly species. Based on all these results we conclude that the MEAM1 species is more invasive due to its genetic variations.

\section{Conclusion}

In present study, whole genome wide variants between Asia II 1 (indigenous to the Indian sub-continent and south-east Asia) and MEAM1 (originated in the Middle East but has spread worldwide in recent decades) are presented with their detailed annotations and impact. Variants detection in some important genes such as genes associated with virus transmission and insecticide resistance will help in conceiving future research towards targeted management strategies against whitefly. Furthermore, this study provides a genomic resource of

Table 8 Structural Variants

\begin{tabular}{lllllll}
\hline Type & scaffold & start & end & length & CNV & Genes* \\
\hline duplication & Scaffold112 & $2,190,001$ & $2,470,000$ & 280,000 & 1.59861 & \\
duplication & Scaffold130 & $2,120,001$ & $2,590,000$ & 470,000 & 1.50412 & Bta02314 Bta02317 Bta02318 Bta02321 Bta02311 Bta02319 Bta02313 Bta02315 \\
& & & & & Bta02320 Bta02322 Bta02312 Bta02316 \\
duplication Scaffold310 & $2,080,001$ & $2,870,000$ & 790,000 & 1.51561 & Bta08154 Bta08157 Bta08159 Bta08153 Bta08161 Bta08158 Bta08160 Bta08155 \\
& & & & & Bta08156 \\
duplication Scaffold343 & $3,950,001$ & $4,160,000$ & 210,000 & 2.19297 & Bta09326 \\
duplication Scaffold403 & $2,470,001$ & $2,980,000$ & 510,000 & 1.55897 & Bta10316 Bta10315 Bta10317 Bta10318 Bta10319
\end{tabular}


Asia II 1 that will contribute to resolving species delimitation of whitefly.

\section{Methods}

\section{Colony maintenance and confirmation of cryptic species}

The source of whitefly (Asia II-1) population collected from NIBGE, Faisalabad in 2016. An isogenic population was established and maintained in aired glass confinement on cotton (Gossypium hirsutum) plants at $32{ }^{\circ} \mathrm{C}$. The universal mtCOI primers C1-J-2195 (5'-TTGATTTTTTGGTCATCCAGAAGT-3') and TL2-N-3014 (5'-TCCAATGCACTAATCTGCCATATTA-3' were used to confirm the cryptic species (Asia II 1) [44]. PCR amplifications were performed in $20 \mu \mathrm{L}$ reactions using DreamTaq Green PCR Master Mix (Thermo Fisher Scientific). The polymerase chain reaction (PCR) cycling parameters were one denaturation cycle of $94{ }^{\circ} \mathrm{C}$ for $5 \mathrm{~min}$, followed by 35 cycles of $94{ }^{\circ} \mathrm{C}$ for $1 \mathrm{~min}, 45^{\circ} \mathrm{C}$ for $1 \mathrm{~min}$, and $72^{\circ} \mathrm{C}$ for $1 \mathrm{~min}$, followed by a final extension of $72{ }^{\circ} \mathrm{C}$ for $7 \mathrm{~min}$. PCR products were visualized on a $1 \%$ agarose gel. Sanger sequencing [45] confirmed the Asia II 1 culture.

\section{Genomic DNA extraction and library preparation}

DNA extraction was done with "ISOLATE II Genomic DNA Kit" (Bioline Cat No. BIO-52066). Eight libraries with $550 \mathrm{bp}$ insert size were prepared by the Illumina NeoPrep automation system with the library kit, Illumina \#NP-101-1001, "TruSeq Nano DNA Library Kit for NeoPrep", which includes the adapter set "TruSeq LT" (adapter sequences: adapter read1 AGATCGGAAGAGCACACGTCTGAACTCCAGTCA, adapter read2 AGAT CGGAAGAGCGTCGTGTAGGGAAAGAGTGT). The target insert size selection was performed by the "Illumina NeoPrep Liberary Prep System". Actual insert size ranges were calculated by CLC Genomics Workbench (v. 8.5.1).

\section{Sequencing and mapping with reference genome}

Sequencing was performed on the Illumina MiSeq and HiSeq2500 with Rapid v2 chemistry, 2x100bp, across 2 flow cell lanes. The Illumina bcl2fastq v2.16 software was used to convert raw basecalls (.bcl) to fastq.gz, and demultiplex the sequenced pool of libraries by the TruSeq LT indices in the NeoPrep process. The bcl2fastq script was set to automatically trim the adapters, if present. All duplicated reads, low quality regions (phred score less than threshold value) and reads containing $\mathrm{N}$ were trimmed. Cleaned reads were mapped onto the total reference genome of whitefly. Reference genome was accessed through $\mathrm{ftp} / /$ www.whiteflygenomics.org/pub/MEAM1/MEAM1/ [4]. Mapping was done using BWA V0.7.12 with MEM algorithm using CLC Genomics Workbench 7.5. Raw data was visualized and analyzed to pass through quality control steps. Variant calling was performed by Haplotype caller GATK (using 'ERC GVCF-variant_index_type
LINEAR -variant_index_parameter 128,000). Variant filtration was performed two times using parameters (filtration1: DP > 20 \& QD > 25.0 \& FS < 5.00, filtration 2: DP > $30 \& \mathrm{QD}>30.0 \& \mathrm{FS}=0.00$ ).

\section{Analysis of variants}

SnpEff [46] was used to annotate variants and effect prediction, and to classify the effects of variants by 'functional classes' (missense, nonsense and silent), by 'impact' (high, moderate, low and modifier), and by 'type and region' (downstream, exon, intergenic, intron, splice site acceptor, splice site donor, splice site region, transcript, upstream, UTR $3^{\prime}$, and UTR 5'). Then all genes that had "high impact variants" were analyzed with "Blast2GO Pro" (trial version) software [47] for gene ontology and to categorize gene functions into three classes: biological process, cellular components and molecular function. With Blast2GO Pro, KEGG pathways of these genes were also developed to analyze their function. All the mapped reads were evaluated to find structural variants. CNVnator [48] was used in the present study to find structural variants. CNVnator analyzes the "read of depth" from alignment to predict the structural variants. Copy number variations were detected by CNVkit [49].

\section{SNPs validation}

Some SNPs were randomly selected for the validation. Eight primer pairs were designed to amplify the regions (each with 500-600 bp length) which have a total of 96 SNPs. DNA was extracted from single whiteflies by the CTAB method [50]. Each region was amplified using DNA extracted from a single whitefly. PCR were performed in $50 \mu \mathrm{L}$ reactions using DreamTaq Green PCR Master Mix (Thermo Fisher Scientific). PCR cycling parameters were one denaturation cycle of $94{ }^{\circ} \mathrm{C}$ for $5 \mathrm{~min}$, followed by 35 cycles of $94{ }^{\circ} \mathrm{C}$ for $1 \mathrm{~min}, 54^{\circ} \mathrm{C}$ for $30 \mathrm{~s}$, and $72{ }^{\circ} \mathrm{C}$ for $40 \mathrm{~s}$, followed by a final extension of $72^{\circ} \mathrm{C}$ for $7 \mathrm{~min}$. PCR products were visualized on a $1 \%$ agarose gel. Amplified products were purified by "AxyPrep PCR Clean-up Kit" and then these were sequenced by the Sanger method [45]. The sequenced reads were aligned with MEAM1 sequences by DNAStar software to validate the predicted SNPs.

We also analyzed the previously published transcriptomic data of MEAM1 [4, 6, 34]. They reported some genes that were associated with virus transmission (TYLCV and ToCV) and insecticide resistance. In our data we identified genes which had high impact variants and as well as genes previously reported as differentially expressed under virus or insecticide treatment. 


\section{Additional files}

Additional file 1: Summary of raw data generated in each library. (XLSX
$9 \mathrm{~kb}$ )

Additional file 2: Variant statistics. Variants statistics describe number of variants and effects and their types. (XLSX $12 \mathrm{~kb}$ )

Additional file 3: BLAST2GO results. Annotations of genes with high impact variants are classified in three main classes (1-biological function, 2-molecular function, 3-cellular components). GO IDs and number of genes in each subclass are also given in this file. (XLSX $22 \mathrm{~kb}$ )

Additional file 4: SNP validation. This file describes the positions of amplified regions in scaffolds and position of validated variants in each amplified region. (XLSX $13 \mathrm{~kb}$ )

Additional file 5: CNVkit results. (XLSX $19 \mathrm{~kb}$ )

Additional file 6: Gene ontology of genes having structural variants. Annotations and InterPro IDs of genes are given. (XLSX $10 \mathrm{~kb}$ )

Additional file 7: Gene IDs of genes contributing in different pathways. (XLSX $12 \mathrm{~kb})$

\section{Abbreviations}

BP: Biological Process; CC: Cellular Component; CTAB: Cetyl Trimethyl Ammonium Bromide; GATK: Genome Analysis Tool Kit; INDELS: Insertions Deletions; MEAM1: Middle East Asia Minor 1; MF: Molecular Function; mtCOI: Mitochondrial Cytochrome Oxidase Subunit l; SNP: Singe Nucleotide Polymorphism; ToCV: Tomato crinivirus; ToLCHnV: Tomato leaf curl Hainan virus; TYLCV: Tomato yellow leaf curl virus

\section{Acknowledgements}

We thank Atiq Ur Rehman, Imran Rauf, Muhammad Hamza Rana, Mariyam Masood and Nasim Ahmed for technical assistance.

\section{Authors' contributions}

$\mathrm{SH}$ and MF has equal contribution in this study. SH performed functional analysis (Blast2GO), SNPs validation and contributed in detection of structural variants. SH also drafted the manuscript. MF performed the genome mapping, variant calling, variant analysis (SnpEff) and detection of structural variants. HJM maintained the whitefly isogenic culture and performed the confirmation of species (Asia II 1) of whitefly. IA contributed in wet lab experiments and computational analysis, and reviewed the manuscript. BS performed the sequencing. SL and JS reviewed and edited the manuscript. SM designed the study and contributed in writing the manuscript. All authors read and approved the final manuscript.

\section{Funding}

This work is supported by the 'Pak-US cotton productivity enhancement program' of the International Center for Agricultural Research in the Dry Areas (ICARDA) funded by United States Department of Agriculture (USDA), Agricultural Research Service (ARS), under agreement 58-6402-0-178F. Any opinions, findings, conclusions, or recommendations expressed in this publication are those of the author(s) and do not necessarily reflect the views of the USDA or ICARDA.

\section{Availability of data and materials}

The raw data of sequencing reads is submitted to SRA database of NCBI. The data can be accessed with these accession numbers: SRR8656460, SRR8656459, SRR8656466, SRR8656463, SRR8656456, SRR8656455, SRR8656458, SRR8656467, SRR8656465, SRR8656464, SRR8656462, SRR8656461, SRR8656457.

\section{Ethics approval and consent to participate}

Not applicable.

\section{Consent for publication}

Not applicable.

\section{Competing interests}

The authors declare that they have no competing interests.

\section{Author details}

${ }^{1}$ National Institute for Biotechnology and Genetic Engineering, Faisalabad, Pakistan. ${ }^{2}$ Department of Biotechnology, Pakistan Institute of Engineering \& Applied Sciences (PIEAS), Nilore, Islamabad, Pakistan. ${ }^{3}$ USDA-ARS, Genomics and Bioinformatics Research Unit, 141 Experiment Station Rd., Stoneville, MS 38776, USA. ${ }^{4}$ USDA-ARS, Crop Genetics Research Unit, 141 Experiment Station Rd, Stoneville, MS 38776, USA. Institute of Insect Sciences, College of Agriculture and Biotechnology, Zhejiang University, Hangzhou 310058, China.

Received: 3 December 2018 Accepted: 31 May 2019

Published online: 18 June 2019

\section{References}

1. Abd-Rabou S, Simmons AM. Survey of reproductive host plants of Bemisia tabaci (Hemiptera: Aleyrodidae) in Egypt, including new host records. Entomol News. 2010;121(5):456-65.

2. Gilbertson RL, Batuman O, Webster CG, Adkins S. Role of the insect supervectors Bemisia tabaci and Frankliniella occidentalis in the emergence and global spread of plant viruses. Annu Rev Virol. 2015;2(1):67-93.

3. Geng L, Qian L-X, Shao R-X, Liu Y-Q, Liu S-S, Wang X-W. Transcriptome profiling of whitefly guts in response to tomato yellow leaf curl virus infection. Virol J. 2018;15:14.

4. Chen W, Hasegawa DK, Kaur N, Kliot A, Pinheiro PV, Luan J, Stensmyr MC, Zheng Y, Liu W, Sun H, et al. The draft genome of whitefly Bemisia tabaci MEAM1, a global crop pest, provides novel insights into virus transmission, host adaptation, and insecticide resistance. BMC Biol. 2016;14(1):110.

5. Yao F-L, Zheng $Y$, Huang $X-Y$, Ding $X-L$, Zhao J-W, Desneux N, He $Y-X$, Weng Q-Y. Dynamics of Bemisia tabaci biotypes and insecticide resistance in Fujian province in China during 2005-2014. Sci Rep. 2017;7:40803.

6. Kaur N, Chen W, Zheng Y, Hasegawa DK, Ling K-S, Fei Z, Wintermantel WM. Transcriptome analysis of the whitefly, Bemisia tabaci MEAM1 during feeding on tomato infected with the crinivirus, tomato chlorosis virus, identifies a temporal shift in gene expression and differential regulation of novel orphan genes. BMC Genomics. 2017;18(1):370.

7. Huipeng P, PE L, Dong C, Shaoli W, Qingjun W, Yves C, Xuguo Z, Youjun Z. Insecticides promote viral outbreaks by altering herbivore competition. Ecol Appl. 2015;25(6):1585-95.

8. Ning W, Shi X, Liu B, Pan H, Wei W, Zeng Y, Sun X, Xie W, Wang S, Wu Q, et al. Transmission of tomato yellow leaf curl virus by Bemisia tabaci as affected by whitefly sex and biotype. Sci Rep. 2015;5:10744.

9. Marubayashi JM, Kliot A, Yuki VA, Rezende JAM, Krause-Sakate R, Pavan MA, Ghanim M. Diversity and localization of bacterial endosymbionts from whitefly species collected in Brazil. PLoS One. 2014;9:9.

10. Qin L, Pan LL, Liu SS. Further insight into reproductive incompatibility between putative cryptic species of the Bemisia tabaci whitefly complex. Insect Sci. 2016;23(2):215-24.

11. Alemandri V, Vaghi Medina CG, DumÓn AD, Argüello Caro EB, Mattio MF, García Medina S, López Lambertini PM, Truol G. Three members of the Bemisia tabaci (Hemiptera: Aleyrodidae) cryptic species complex occur sympatrically in argentine horticultural crops. J Econ Entomol. 2015;108(2):405-13.

12. Dinsdale A, Cook L, Riginos C, Buckley YM, De Barro P. Refined global analysis of Bemisia tabaci (Hemiptera: Sternorrhyncha: Aleyrodoidea: Aleyrodidae) mitochondrial cytochrome oxidase 1 to identify species level genetic boundaries. Ann Entomol Soc Am. 2010;103(2):196-208.

13. Firdaus $S$, Vosman B, Hidayati N, Jaya Supena ED, Visser RG, van Heusden AW. The Bemisia tabaci species complex: additions from different parts of the world. Insect Sci. 2013;20(6):723-33.

14. Luan J-B, Li J-M, Varela N, Wang Y-L, Li F-F, Bao Y-Y, Zhang C-X, Liu S-S, Wang X-W. Global analysis of the transcriptional response of whitefly to tomato yellow leaf curl China virus reveals the relationship of coevolved adaptations. J Virol. 2011;85(7):3330-40.

15. Czosnek H, Hariton-Shalev A, Sobol I, Gorovits R, Ghanim M. The incredible journey of begomoviruses in their whitefly vector. Viruses. 2017;9(10):273

16. Hogenhout SA, Ammar el D, Whitfield AE, Redinbaugh MG. Insect vector interactions with persistently transmitted viruses. Annu Rev Phytopathol. 2008;46:327-59.

17. Pan L, Chen Q, Guo T, Wang X, Li P, Wang X, Liu S. Differential efficiency of a begomovirus to cross the midgut of different species of whiteflies results in variation of virus transmission by the vectors. Sci China Life Sci. 2018; 61(10):1254-65. doi: https://doi.org/10.1007/s11427-017-9283-4. 
18. Götz M, Popovski S, Kollenberg M, Gorovits R, Brown JK, Cicero JM, Czosnek H, Winter S, Ghanim M. Implication of Bemisia tabaci heat shock protein 70 in begomovirus-whitefly interactions. J Virol. 2012;86(24):13241-52.

19. Hariton Shalev A, Sobol I, Ghanim M, Liu S-S, Czosnek H. The whitefly Bemisia tabaci Knottin-1 gene is implicated in regulating the quantity of tomato yellow leaf curl virus ingested and transmitted by the insect. Viruses. 2016;8(7):205.

20. Kanakala S, Ghanim M. Implication of the whitefly Bemisia tabaci cyclophilin B protein in the transmission of tomato yellow leaf curl virus. Front Plant Sci. 2016;7:1702.

21. Wang Z-Z, Shi M, Huang Y-C, Wang X-W, Stanley D, Chen X-X. A peptidoglycan recognition protein acts in whitefly (Bemisia tabaci) immunity and involves in begomovirus acquisition. Sci Rep. 2016;6:37806.

22. Baumann P, Munson MA, Lai C-Y, Clark MA, Baumann L, Moran N, Campbell BC. Origin and properties of bacterial endosymbionts of aphids, whiteflies, and mealybugs. ASM News. 1993;59:21-4.

23. De Barro PJ, Liu S-S, Boykin LM, Dinsdale AB. Bemisia tabaci: a statement of species status. Annu Rev Entomol. 2010;56(1):1-19.

24. Liu S-S, Colvin J, De Barro PJ. Species concepts as applied to the whitefly Bemisia tabaci systematics: how many species are there? J Integr Agric. 2012;11(2):176-86.

25. Ashfaq M, Hebert PDN, Mirza MS, Khan AM, Mansoor S, Shah GS, Zafar Y. DNA barcoding of Bemisia tabaci complex (Hemiptera: Aleyrodidae) reveals southerly expansion of the dominant whitefly species on cotton in Pakistan. PLoS One. 2014:9(8):104485.

26. Masood M, Amin I, Hassan I, Mansoor S, Brown JK, Briddon RW. Diversity and distribution of cryptic species of the Bemisia tabaci (Hemiptera: Aleyrodidae) complex in Pakistan. J Econ Entomol. 2017;110:2295-300.

27. Li M, Hu J, Xu F-C, Liu S-S. Transmission of tomato yellow leaf curl virus by two invasive biotypes and a Chinese indigenous biotype of the whitefly Bemisia tabaci. Int J Pest Manag. 2010;56(3):275-80.

28. Götz M, Winter S. Diversity of Bemisia tabaci in Thailand and Vietnam and indications of species replacement. J Asia Pac Entomol. 2016;19(2):537-43.

29. Pan L-L, Cui X-Y, Chen Q-F, Wang X-W, Liu S-S. Cotton leaf curl disease: which whitefly is the vector? Phytopathology. 2018;108(10):1172-83.

30. Naveen NC, Chaubey R, Kumar D, Rebijith KB, Rajagopal R Subrahmanyam B, Subramanian S. Insecticide resistance status in the whitefly, Bemisia tabaci genetic groups Asia-I, Asia-II-1 and Asia-II-7 on the Indian subcontinent. Sci Rep. 2017;7:40634.

31. Ahmed MZ, Naveed M, Noor ul Ane M, Ren SX, De Barro P, Qiu BL. Host suitability comparison between the MEAM1 and Asiall 1 cryptic species of Bemisia tabaci in cotton-growing zones of Pakistan. Pest Manag Sci. 2014;70(10):1531-7.

32. Schuster SC. Next-generation sequencing transforms today's biology. Nat Methods. 2007:5(1):16.

33. Chen W, Hasegawa D, Arumuganathan K, Simmons A, Wintermantel W, Fei Z, Ling K-S. Estimation of the whitefly Bemisia tabaci genome size based on k-mer and flow cytometric analyses. Insects. 2015;6(3):704.

34. Hasegawa DK, Chen W, Zheng Y, Kaur N, Wintermantel WM, Simmons AM, Fei Z, Ling K-S. Comparative transcriptome analysis reveals networks of genes activated in the whitefly, Bemisia tabaci when fed on tomato plants infected with tomato yellow leaf curl virus. Virology. 2018;513:52-64.

35. Elfekih S, Etter P, Tay WT, Fumagalli M, Gordon K, Johnson E, De Barro P. Genome-wide analyses of the Bemisia tabaci species complex reveal contrasting patterns of admixture and complex demographic histories. PLoS One. 2018;13(1):0190555

36. Vyskočilová S, Tay WT, van Brunschot S, Seal S, Colvin J. An integrative approach to discovering cryptic species within the Bemisia tabaci whitefly species complex. Sci Rep. 2018;8(1):10886.

37. Seger R, Krebs EG. The MAPK signaling cascade. FASEB J. 1995;9(9):726-35.

38. Awmack CS, Leather SR. Host plant quality and fecundity in herbivorous insects. Annu Rev Entomol. 2002;47:817-44.

39. Byrne DN, Miller WB. Carbohydrate and amino acid composition of phloem sap and honeydew produced by Bemisia tabaci. J Insect Physiol. 1990;36(6):433-9.

40. J. X, K. LK, S. LS. Performance on different host plants of an alien and an indigenous Bemisia tabaci from China. J Appl Entomol. 2011;135(10):771-9.

41. Carabali A, Bellotti AC, Montoya-Lerma J, Cuellar ME. Adaptation of Bemisia tabaci biotype B (Gennadius) to cassava, Manihot esculenta (Crantz). Crop Prot. 2005;24(7):643-9.

42. Yang X, Xie W, Wang S-L, Wu Q-J, Pan H-P, Li R-M, Yang N-N, Liu B-M, Xu B$Y$, Zhou $X$, et al. Two cytochrome P450 genes are involved in imidacloprid resistance in field populations of the whitefly, Bemisia tabaci, in China. Pest Biochem Physiol. 2013;107(3):343-50.

43. Shukla E, Thorat LJ, Nath BB, Gaikwad SM. Insect trehalase: physiological significance and potential applications. Glycobiology. 2015;25(4):357-67.

44. Simon C, Frati F, Beckenbach A, Crespi B, Liu H, Flook P. Evolution, weighting, and phylogenetic utility of mitochondrial gene sequences and a compilation of conserved polymerase chain reaction primers. Ann Entomol Soc Am. 1994;87(6):651-701.

45. Sanger F, Nicklen S, Coulson AR. DNA sequencing with chain-terminating inhibitors. Proc Natl Acad Sci U S A. 1977;74(12):5463-7.

46. Cingolani P, Platts A, Wang LL, Coon M, Nguyen T, Wang L, Land SJ, Lu X, Ruden DM. A program for annotating and predicting the effects of single nucleotide polymorphisms, SnpEff. Fly. 2012;6(2):80-92.

47. Conesa A, Götz S, García-Gómez JM, Terol J, Talón M, Robles M. Blast2GO: a universal tool for annotation, visualization and analysis in functional genomics research. J Bioinform. 2005;21(18):3674-6.

48. Abyzov A, Urban AE, Snyder M, Gerstein M. CNVnator: an approach to discover, genotype, and characterize typical and atypical CNVs from family and population genome sequencing. Genome Res. 2011;21(6):974-84.

49. Talevich E, Shain AH, Botton T, Bastian BC. CNVkit: genome-wide copy number detection and visualization from targeted DNA sequencing. PLoS Comput Biol. 2016:12(4):1004873.

50. Clarke JD. Cetyltrimethyl ammonium bromide (CTAB) DNA miniprep for plant DNA isolation. Cold Spring Harb Protoc. 2009;2009(3):pdb.prot5177. doi: https://doi.org/10.1101/pdb.prot5177.

\section{Publisher's Note}

Springer Nature remains neutral with regard to jurisdictional claims in published maps and institutional affiliations.
Ready to submit your research? Choose BMC and benefit from:

- fast, convenient online submission

- thorough peer review by experienced researchers in your field

- rapid publication on acceptance

- support for research data, including large and complex data types

- gold Open Access which fosters wider collaboration and increased citations

- maximum visibility for your research: over $100 \mathrm{M}$ website views per year

At BMC, research is always in progress.

Learn more biomedcentral.com/submissions 